\title{
Neonatal Omphalitis in Iraq
}

\author{
Hiba Sabah Jasim ${ }^{1}$, Sevan Najem Alwan ${ }^{1}$, Yasmeen Jawad Al-Bayaa ${ }^{1}$ \\ (Department of microbiology, College of medicine/University of Baghdad, Iraq)
}

\begin{abstract}
In developed countries aseptic delivery techniques, hygienic cord care and prompt antimicrobial therapy have decreased the occurrence as well as the severity of Omphalitis. However, the condition remains a significant cause of morbidity and mortality in the developing country. The objective is the risk factors, clinical and bacteriological profile of neonates with Omphalitis in Iraq. Regarding the patients sixty-four neonatal Omphalitis admitted at the Neonatal Intensive Care Units of Children Welfare Teaching Hospital and Neonatal Intensive Care Units of Al-elwya Teaching Hospital in Baghdad Iraq, during 8 months from October 2011 to May 2012. The risk factors and clinical, bacteriologic and relevant investigational profiles and outcomes were studied in neonates with Omphalitis. For the study purpose Omphalitis was classified into four categories based on severity. The result was show that the incidence of Omphalitis was higher in home births and in neonates with low birth weight. Staphylococcus aureus was the most common pathogen isolated from umbilical swabs followed by Escherichia coli. Regarding conclusion low birth weight and home delivery are considered as risk factors for Omphalitis in Iraq. The treatment should be received for Gram-positive and Gram-negative microorganism because of the predominance of Gram-negative microorganisms in neonatal infant with Omphalitis.
\end{abstract}

Keywords: Neonates, Omphalitis, Risk Factors, Newborn infection, Umbilical culture.

\section{Introduction}

Omphalitis is an infection that affects the umbilical stump. Omphalitis generally manifests as a cellulitis that is superficial in nature. The disease may spread to include the complete wall of the abdomen. It can give rise to a number of complications, such as necrotizing fasciitis, systemic disease, and myonecrosis [1-3].

Necrotic tissue of the umbilical cord is an excellent medium for bacterial growth and become rapidly colonized by bacteria from the maternal genital tract and from the environment soon after birth [4].The umbilical vessels in a necrotic infected cord provide microbial pathogens direct access to the blood stream [5]. The evident of aseptic techniques and introduction of antimicrobial agents greatly reduced the occurrence of umbilical infections in the newborn [6]. Neonatal Omphalitis has become an uncommon infection in developed countries. However, the condition remains a significant cause of morbidity and mortality in the developing world [7]. There are only a few recent studies on neonatal Omphalitis from developing countries [7-9], and scarce reports from the developed world $[10,11]$. Although, reliable estimates of the incidence of Omphalitis are not available $[7,10,11]$. The present study aims at presenting new data on neonatal Omphalitis from Iraq.

\section{Patients and Methods}

The study was conducted at the Neonatal Intensive Care Units of Children Welfare Teaching Hospital and Neonatal Intensive Care Units of Al-elwya Teaching Hospital in Baghdad, Iraq. Sixty-four neonate aged 1 hour-28 days, males and females, during 8 months from October 2011 to May 2012.The patients were clinically suspected of having Omphalitis. The sixty-four neonate with bacteriologically proved Omphalitis were evaluated for birth history, physical finding, white blood cell (WBC) count, body weight according to the standard reference curves $[12,13]$ bacterial etiology and outcome. For the study purpose neonatal Omphalitis was graded in four categories:

1. Funisitis, umbilical discharge (shaggy unhealthy umbilical stump, malodorous and/ or purulent discharge).

2. Omphalitis with abdominal wall cellulitis (periumbilical erythema, superficial tenderness.

3. Omphalitis with systemic (if in addition to category 1 and/ or 2 feature of generalized systemic involvement were present).

4. Omphalitis with fasciitis (if there was umbilical necrosis with extensive local disease, periumbilical ecchymosis, crepitus bullae and evidence of involvement of superficial and deep fascia).

Specimens were obtained with a sterile cotton swab from the cord-cutaneous junction and/ or the purulent discharge from the umbilicus. All materials were sent in an anaerobic transport medium to the microbiology laboratory and cultured within $60 \mathrm{~min}$. Aerobic culture media included plates of blood agar, chocolate agar and MacConkey agar. All plates were incubated at $37^{\circ} \mathrm{C}$; the MacConkey plates aerobically and the other plates under $5-10 \% \mathrm{CO}_{2}$. Anaerobic media consisted of anaerobic blood agar plates, incubated at $37^{\circ}$ 
$\mathrm{C}$ in Gas Pak jars. Plates incubated aerobically were examined at 24 and $48 \mathrm{hr}$. For blood culture approximately One to $5 \mathrm{ml}$ blood (according to the condition of the neonate) were aspirated from each neonate, and divided into two parts; the first part for aerobic blood culture bottle (brain heart infusion), and remain blood was inoculated in anaerobic blood culture bottle (thioglycolate) Few drops of primary culture were subcultured into secondary culture media blood agar, chocolate agar and MacConkey agar, and then the media were inspected for the presence of bacterial growth. All organisms isolated from swabs (from the cord-coetaneous junction and/ or the purulent discharge from the umbilicus ) and blood culture bottles were identified using Gram stain morphology and standard biochemical testing and confirmed by API-20E biotyping and API 20E system [14, 15].

\section{Results}

The demographic and historic data of the patients according to the category of Omphalitis are shown in Table [1]; there were 34 male and 30 female neonates with Omphalitis with a male: female ratio of (1.13:1), the male were more than female in the total of all three groups. There were no neonates under category 4 so it was excluded from the study. The mean age at presentation was similar in the three groups. Of 64 neonates $12(18.75 \%)$ were of low birth weight $(<2500 \mathrm{~g})$. A significant association was observed between low birth weight and Omphalitis in the study $(P<0.001)$. Home delivery, which is usually under nonsterile conditions, was 37(57.8) of 64 neonates of Omphalitis. There was a significant association between home delivery and Omphalitis $(P<0.05)$. Umbilical catheterization was associated with only $2(3.1 \%)$ cases of Omphalitis and was not significant factor in this study.

Table 1: Historic data of Neonates with Omphalitis

\begin{tabular}{|c|c|c|c|c|c|c|}
\hline Categories & $\begin{array}{c}\text { Total No. of } \\
\text { Cases }\end{array}$ & Sex (M/F) & $\begin{array}{c}\text { Age at } \\
\text { Presentation } \\
\text { (Days) } \\
\text { (mean } \pm \text { SD) }\end{array}$ & $\begin{array}{c}\text { Birth Wight } \\
<2500 \mathrm{~g}\end{array}$ & $\begin{array}{c}\text { Home } \\
\text { Delivery }\end{array}$ & $\begin{array}{c}\text { Umbilical } \\
\text { Catheterization }\end{array}$ \\
\hline 1 & 25 & $\begin{array}{c}14 / 11 \\
(1.27 / 1)\end{array}$ & $7.1 \pm 4.8$ & $3(12)^{*}$ & $13(52)$ & - \\
\hline 2 & 28 & $\begin{array}{c}13 / 15 \\
(0.8 / 1)\end{array}$ & $6.9 \pm 5.7$ & $5(17.8)$ & $16(57.1)$ & $2(8)$ \\
\hline 3 & 11 & $\begin{array}{c}7 / 4 \\
(1.75 / 1)\end{array}$ & $5.9 \pm 2.7$ & $4(36.4)$ & $8(72.7)$ & - \\
\hline 4 & - & - & - & - & - & - \\
\hline Total & 64 & $\begin{array}{c}34 / 30 \\
(1.13 / 1)\end{array}$ & & $12(18.75)$ & $37(57.8)$ & $2(3.1)$ \\
\hline
\end{tabular}

The presenting physical findings are shown in Table [2]. In the first Omphalitis category, there were no symptoms or local signs. In the second Omphalitis category there were local signs that were fever and abdominal distension in few cases but no generalized symptoms or signs of sepsis. In category 3 , most of the affected neonates had constitutional signs and symptoms. An abnormal leukocyte count was observed in $5(45.5 \%)$ and septicemia in 6(54.5\%) of neonates in third category with $(P<0.05)$ for each one. The jaundice was present in 29(45.3\%) of all Omphalitis in the three categories. Table [2] also shows 4(36.4\%) of the 11 patients in category 3 with systemic symptoms were died despite appropriate antibiotic therapy.

Table 2: Physical Finding and Investigations in Neonates with Omphalitis

\begin{tabular}{|c|c|c|c|c|c|c|c|c|c|c|}
\hline Categories & $\begin{array}{l}\text { Total } \\
\text { No. } \\
\text { of } \\
\text { Cases }\end{array}$ & $\begin{array}{c}\text { Temperature } \\
\left(\leq 36 \mathrm{C}^{\circ} \text { or } \geq\right. \\
\left.38 \mathrm{C}^{\circ}\right)\end{array}$ & $\begin{array}{l}\text { Pulse } \\
(> \\
180)\end{array}$ & $\begin{array}{c}\text { Hypotension } \\
\text { (Systolic } \\
\text { Bp } \leq 160)\end{array}$ & Jaundice & $\begin{array}{l}\text { Abdominal } \\
\text { Distension }\end{array}$ & $\begin{array}{c}\text { Total } \\
\text { Leukocyte } \\
\text { Count }(<4 \\
\times 10^{3} \text { or } \\
>30 \\
\left.\times 10^{3} / \mathrm{mm}^{2}\right)\end{array}$ & Septicemia & $\begin{array}{l}\text { Positive } \\
\text { Umbilical } \\
\text { Swab } \\
\text { Culture }\end{array}$ & Morality \\
\hline 1 & 25 & $4(16)^{*}$ & - & - & $10(40)$ & $1(4)$ & $1(4)$ & - & $23(92)$ & - \\
\hline 2 & 28 & $9(32.1)$ & - & - & $11(39.2)$ & $3(10.7)$ & $2(7.1)$ & $1(3.6)$ & $26(92.9)$ & - \\
\hline 3 & 11 & $7(63.6)$ & $4(36.4)$ & $4(36.4)$ & $8(72.7)$ & $7(63)$ & $5(45.5)$ & $6(54.5)$ & $11(100)$ & $4(36.4)$ \\
\hline
\end{tabular}

Table 3: Bacterial Isolates from Positive Umbilical Swab Culture

\begin{tabular}{|c|c|c|c|c|}
\hline $\begin{array}{c}\text { Bacterial } \\
\text { Microorganisms }\end{array}$ & $\begin{array}{c}\text { Physical Finding } 1 \text { ( } 23 \\
\text { positive Umbilical } \\
\text { Swab Culture) }\end{array}$ & $\begin{array}{c}\text { Physical Finding } 2 \text { (26 } \\
\text { positive Umbilical } \\
\text { Swab Culture) }\end{array}$ & $\begin{array}{c}\text { Physical Finding } 3 \\
\text { (11 positive Umbilical } \\
\text { Swab Culture) }\end{array}$ & Total \\
\hline Staphylococcus aureus & $11(47.83)$ & $12(46.16)$ & $7(63.6)$ & $30(46.88)$ \\
\hline $\begin{array}{l}\text { Coagulase -negative } \\
\text { staphylococci }\end{array}$ & $3(13.04)$ & $3(11.54)$ & $1(9.1)$ & $7(10.9)$ \\
\hline Alpha-streptococci & $1(4.35)$ & $2(7.7)$ & $1(9.1)$ & $4(6.25)$ \\
\hline Group B streptococci & - & - & - & - \\
\hline E. coli & $3(13.04)$ & $3(11.54)$ & $2(18.2)$ & $8(12.5)$ \\
\hline Klebseilla spp. & $3(13.04)$ & $3(11.54)$ & - & $6(9.37)$ \\
\hline
\end{tabular}




\begin{tabular}{|c|c|c|c|c|}
\hline Proteus mirabilis & - & $1(3.85)$ & - & $1(1.6)$ \\
\hline Pseudomonas spp. & $2(8.7)$ & $2(7.7)$ & - & $4(6.25)$ \\
\hline & $23(92)$ & $26(92.9)$ & $11(100)$ & $60(93.75)$ \\
\hline
\end{tabular}

Table [3] shows the organisms were isolated from umbilical swab cultures, bacteria were isolated in 60(93.75\%) of 64 cases of neonatal Omphalitis Staphylococcus aureus was found in 30(46.88\%) of bacterial isolates, followed by Escherichia coli in 8(12.5\%), Coagulase- negative staphylococci was $7(10.9 \%)$ and Klebseilla spp. was 6(9.37\%), the Alpha-streptococci and Pseudomonas spp. were 4(6.25\%) and one isolates $(1.6 \%)$ of Proteus mirabilis. In 5 cases $(8.3 \%)$ there was poly microbial growth. The organisms isolate from blood culture were matched with organisms recovered from umbilical discharge cultures in all cases.

\section{Discussion}

This study demonstrates that there is a significant association between home deliveries and Omphalitis $(P<0.001)$. Reduction in neonatal Omphalitis is in parallel with reduction in home births. This is in agreement with reports from Middle East $[7,8,16]$. This study also shows low birth weight as a risk factor of Omphalitis because; there is a significant association between low birth weight and Omphalitis $(P<0.001)$, this finding agrees with Davies [17] who reports that low birth weight has an important role in the genesis of Omphalitis in both hospital and home-born neonates. This study found that the associated between the Umbilical catheterization and Omphalitis was only 2(3.1\%) cases of Omphalitis so it was not significant factor in this study. This finding agrees with Guvenc [8] who found that the umbilical catheterization has no significant association with Omphalitis in Eastern Turkey. This finding also disagrees with the finding of Davies [17] who reported that the risk factors for neonatal Omphalitis were included low birth weight, home delivery and prior umbilical catheterization, this may be due to that the report was presented at 1972 which was enough time to developed the country in aseptic delivery techniques, hygienic cord care and prompt antimicrobial therapy $[6,10]$.

In this study the ratio of abnormal leukocyte count in the funisitis/umbilical discharge and cellulites (category.1 and category.2) was $1(4 \%)$ and $2(7.1 \%)$ respectively which is agrees with other study that found the WBC counts in peripheral blood were within normal limits [8 ], in contrast in Omphalitis with systemic sepsis (category .3), an abnormal leukocyte count was observed in $5(45.5 \%)$ of cases $(P<0.05)$ this finding is agrees with the finding of Kiran [16] who found an abnormal leukocyte count in neonatal Omphalitis with systemic sepsis. Jaundice was present in 29(45.3\%) of cases in all categories and was a result of the high prevalence of glucose-6-phophate dehydrogenase deficiency in the study population [12]. Morality rate in this study was 4(36.4\%); all deaths were observed in patients with neonates who had development of systemic symptoms. That agrees with other studies that found the development of systemic symptoms in additional to home delivery, low birth weight and abnormal temperature at high risk for poor prognosis $[8,9]$.

Bacteriological analysis of umbilical stumps, from newborns with Omphalitis in this study, has revealed that Staphylococcus aureus and Escherichia coli are the most commonly isolated microorganisms. In addition to a slight predominance of Gram-negative microorganisms coagulase- negative staphylococci was $7(10.9 \%)$ and Klebseilla spp. was $6(9.37 \%)$. This finding is agrees with the finding of other study from Middle East $[8,16]$ while other studies have revealed that Staphylococcus aureus, Staphylococcus albus and Streptococcus pyogenes were the most commonly isolated microorganisms[12, 19,20 ]. This may be due to that, in the past two decades with the routine practice of anti staphylococcal cord care [21] with agents such as triple dye, hexachlorophene and alcohol, Gram-negative colonization and infections of the umbilical stump have increased [10].

\section{Conclusion}

The most important physical findings for defining omphalitis are birth weight and home delivery. Regarding local signs jaundice considered the effective one. Presence of microorganisms in umbilical swab culture especially bacteria mean the presence of infection. It is important to be aware of the rare but potentially lethal complications of omphalitis.

\section{Reference}

[1] K Lally, J Atkinson, M Wooley, G Mahour. Necrotizing fasciitis: a serious sequela of omphalitis in the newborn. Ann Surg,199,1984, 101-3.

[2] Samuel M, Freeman N, Vaishnav A, Sajwany M, Nayar M. Necroting fasciitis: a serious complication of omphalitis in neonates. $J$ Pediatr Surg; 29, 1994, 1414-6.

[3] I Monu, A Okolo. Neonatal necrotizing fasciitis: a complication of poor cord hygiene: report of three cases. Ann Trop Pediatr; 10, 1990, 299-303.

[4] S.P.Gotaff. Infections of the neonatal infant. In: R Behrman (Ed), Nelson textbook of pediatrics,16 (Philadelphia: Saunders ,2001): 544.

[5] Forshall I .Septic umbilical arteritis. Arch Dis Child, 32,1957, 25-30. 
[6] Stoll B. The global impact of neonatal infection. Clin Perinatol, 24,1997, 1-2.

[7] Faridi M, Rattan A, Ahmad S. Omphalitis neonatorum. J Indian Med Assoc, 91, 1993, 283-5.

[8] Guvenc H, Guvenc M, Yenioglu H, Ayata A, Kocabay K, Bektas S. Neonatal omphalitis is still commin in Eastern Turkey. Scand J Infect Dis. 23, 1991, 613-7.

[9] Guvene H, Aygun A, Yasar F, Soylu F, Guvenc M, Kocabay K. Omphalitis in term and preterm appropriate for gestational age and small for gestational age infants. J Trop Pediatr; 43, 1997, 368-72.

[10] Mason W, Andrews R, Ross L, Wright H. Omphalitis in the newborn infant. Pediatr Infect Dis J. 8, 1989, 521-5.

[11] Cushing A. Omphalitis: a review. Pediatr Infect Dis, 4, 1985, 282-5.

[12] Mckenna H, Johnson D. Bacteria in neonatal omphalitis. Pathology, 9, 1977, 111-13.

[13] Lubchenco L, Hansman C, Boyd E. The Colorado curves give percentiles of intrauterine growth for weight, length and head circumference. Pediatrics, 37, 16,403.

[14] Al-Shamahy H, Sabrah A., Al-Robasi A, and Naser S. Types of Bacteria associated with Neonatal Sepsis in Al-Thawra University Hospital, Sana'a, Yemen, and their Antimicrobial Profile. Sultan Qaboos Univ Med. J. 12(1), 2012, 48-54.

[15] Tallur S., Kasturi A., Nadgir S., and Krishna B. Clinico-bacteriological study of neonatal septicemia in Hubli. . Indian. J. of Pediatr. 67(3), 2000, 169-174.

[16] Kiran P, Sawardekar, M, Mrcpch. Changing spectrum of neonatal omphalitis. Pediatr Infect Dis J, 23, 2004, 22-6.

[17] Davies P. Infection of the embryo, fetus and newborn. Br J Hosp Med; 8, 1972, 13-26.

[18] National Genetic Blood Disorder Survery,1985. Ministry of Health, Sultanate of Oman: 34.

[19] P Gardner, H.T. Provine. Microbiology for clinicians. In: Manual of acute bacterial infections, 2 (Boston: Little, Brown and Company 1987), 328-329.

[20] Geil C, Castle W, Mortimer E. Group A streptococcal infections in newborn nurseries. Pediatrics, 96, 1970, 849-854.

[21] Chalmers I.1988. Triple dye on the umbilical cord. In: Chalmers I, ed. Oxford database of perinatal trials. Oxford, UK: Oxford University Press. 